\title{
Lidil
}

Revue de linguistique et de didactique des langues

$62 \mid 2020$

Recherches actuelles en didactique du lexique : avancées, réflexions, méthodes

\section{Danièle Manesse et Gilles Siouffi (dir.), Le féminin et le masculin dans la langue : l'écriture inclusive en questions}

Paris, ESF Sciences humaines, 2019, 208 p.

\section{Claire Hugonnier}

\section{(2) OpenEdition}

Journals

Édition électronique

URL : http://journals.openedition.org/lidil/8172

DOI : $10.4000 /$ lidil. 8172

ISSN : $1960-6052$

Éditeur

UGA Éditions/Université Grenoble Alpes

Édition imprimée

ISBN : 978-2-37747-226-0

ISSN : 1146-6480

Référence électronique

Claire Hugonnier, « Danièle Manesse et Gilles Siouffı (dir.), Le féminin et le masculin dans la langue: l'écriture inclusive en questions », Lidil [En ligne], 62 | 2020, mis en ligne le 03 novembre 2020, consulté le 05 novembre 2020. URL : http://journals.openedition.org/lidil/8172 ; DOI : https://doi.org/10.4000/ lidil.8172

Ce document a été généré automatiquement le 5 novembre 2020.

(c) Lidil 


\section{Danièle Manesse et Gilles Siouffi (dir.), Le féminin et le masculin dans la langue : l'écriture inclusive en questions}

Paris, ESF Sciences humaines, 2019, 208 p.

\section{Claire Hugonnier}

\section{RÉFÉRENCE}

Danièle Manesse et Gilles Siouffi (dir.), Le féminin et le masculin dans la langue : l'écriture inclusive en questions, Paris, ESF Sciences humaines, 2019, 208 p.

1 L'ouvrage de Danièle Manesse et Gilles Siouffi a pour ambition d'examiner le champ de discussion autour de l'écriture inclusive en France, afin d'en saisir les enjeux et les processus linguistiques. Ce mode d'écriture alternatif se définit par des ajustements graphiques et syntaxiques proposés en réponse aux accusations de manque de visibilité égalitaire entre les genres féminin et masculin en français. Cet essai a donc moins vocation d'apporter des éléments définitoires de ce qu'est l'écriture inclusive, que d'en comprendre les sources de revendications - motrices de cette pratique sociale - à travers les apports des sciences du langage. Dès l'introduction, le positionnement adopté est explicité: les contributions des différents linguistes se proposent "d'argumenter, pour essayer de soustraire ce sujet [...] aux passions que les luttes pour la dignité des femmes dans nos sociétés peuvent susciter, et aux effets d'idéologie » (p.9). Le volume se structure en trois grandes parties, elles-mêmes sousdivisées en chapitres.

2 La première partie propose des réflexions générales autour du français, en mobilisant les notions d'usages, de normes et de niveaux de langue. La contribution de Gilles Siouffi résonne comme un propos introductif, dans lequel l'auteur semble distiller un avis dubitatif sur les implications de l'écriture inclusive. Selon l'auteur, cette pratique d'écriture témoigne d'un changement de paradigme, dans lequel le signifiant occupe 
une place plus importante que le signifié (p. 31). Il déplore que les mots et les formes graphiques fassent «leur chemin en tant que formes, à côté de leurs fonctions d'origine" (ibid.) - bouleversant ainsi les conditions langagières de manière significative. Gilles Siouffi pense l'écriture inclusive comme une "manière de faire » (p. 26), impliquant un contexte et un usage local, qui ne doit donc pas nécessairement faire l'objet d'une normalisation (p. 34). Danièle Manesse interroge, quant à elle, les conséquences de l'écriture inclusive sur l'oralisation et l'enseignement de la langue. Pour l'auteure, les aménagements proposés (trait d'union, point médian, etc.) « touchent à la nature de ce que sont les caractéristiques de la langue écrite, à la nature des liens à la langue orale qui la précède, à la configuration ordinaire des signes de l'écrit [...]» (p. 55). De ce fait, en créant cette distanciation entre la langue écrite et la langue orale, l'écriture inclusive accroit considérablement la quantité d'éléments non prononcés et complique, par conséquent, le système d'orthographe et l'opération de lecture à haute voix (p. 45). Selon elle, ces caractères, désignés comme «byzantin[s] et contraint[s] » (p.51), ne sont pas une réponse pertinente pour la construction d'une écriture égalitaire; "on ne change pas le système de la langue en l'enrichissant de manière pragmatique de termes pour désigner les activités ou les places des femmes » (p. 55).

3 La deuxième partie aborde l'histoire du français. La contribution de Bernard Colombat donne à voir les évolutions linguistiques des accords depuis le latin; l'auteur, en comparant celui-ci au français, tente de montrer l'incohérence du lien opéré entre la construction d'une langue et la hiérarchisation des sexes au sein d'une société. André Chervel signe ensuite deux articles, qui relatent respectivement le rôle du morphème masculin et l'histoire de l'accord de proximité, autrefois utilisé. Rejoignant Bernard Colombat, il évoque un débat «sans intérêt » (p. 114); d'après lui, « démasculiniser la langue française, c'est vouloir la détricoter » (ibid.).

La troisième partie ambitionne d'apporter des éléments de compréhension à partir de pratiques observées dans des langues étrangères. Les chapitres de la troisième partie traitent respectivement des cas de l'anglais, de l'allemand, de l'arabe et du coréen. Elise Mignot énonce les aménagements opérés en anglais pour rendre la langue égalitaire (suppression des prénoms, jeux de mots, choix du pronom, etc.) ; la neutralisation des marqueurs de genre semble être la méthodologie choisie dans l'usage actuel. Elle évoque également sa perplexité personnelle et politique à l'égard de cette pratique (p. 140). Pour Peter Eisenber, l'écriture inclusive représente «la lutte du genderisme contre le masculin générique » (p.175). En allemand, l'utilisation d'un astérisque ou d'un «I interne" pour manifester la distinction de genre est encore très peu développée. L'auteur en est persuadé, ce combat féministe "ne peut pas être gagné " (ibid.). Pour l'arabe et le coréen, Leda Mansour et Joung Eun Rim signent des articles plus courts. Leurs contributions présentent une synthèse des récents débats nationaux et interrogent la place du genre et l'usage des morphèmes féminins dans la catégorisation des noms de profession notamment. Les auteures évoquent une importance relative des marqueurs de genre et l'absence d'équivalents dans l'arabe et le coréen des problématiques soulevées par l'écriture inclusive en français.

En somme, sur ce " champ de bataille » (p. 9) que constitue la légitimation de l'écriture inclusive, l'intégralité des textes semble avoir choisi le même camp. L'ouvrage achoppe sur un de ses objectifs, celui de soustraire ce sujet aux effets d'idéologie. Il semble, au contraire, prouver la complexité, voire l'impossibilité, de détacher ce sujet de sa 
portée idéologique, car avant d'être une affaire de linguistique, l'application de l'écriture inclusive est d'abord un geste politique. Davantage de pluralité dans les études présentées aurait été souhaitable, permettant ainsi à un public initié ou non d'appréhender toute la complexité des débats, se déroulant au sein même de la communauté des linguistes. Car, de fait, l'ouvrage donne l'image d'un débat unanime et univoque sur l'illégitimité de l'écriture inclusive; or, d'autres linguistes défendent l'utilisation de cette pratique. Ainsi, si ce volume souhaitait clore la polémique, nul doute qu'il donne plutôt matière à (re)débattre.

\section{AUTEURS}

\section{CLAIRE HUGONNIER}

LIDILEM (EA 609), Université Grenoble Alpes 